\title{
Stability Analysis of Solar Cell Characteristics Above Room Temperature Using Indium Nitride Based Quantum Dot
}

\author{
${ }^{1}$ Mohd Abdur Rashid, ${ }^{1}$ Adawati Yusuf, ${ }^{1}$ Md. Abdullah Al Humayun, \\ ${ }^{1}$ Abdul Kareem Naser Mahmood Al-Khateeb and ${ }^{2}$ Shiro Tamaki \\ ${ }^{1}$ School of Electrical Systems Engineering, University Malaysia Perlis, Perlis, Malaysia \\ ${ }^{2}$ Graduate School of Engineering and Science, Faculty of Engineering, University of the Ryukyus, Okinawa, Japan
}

Received 2013-06-10, Revised 2013-08-30; Accepted 2013-09-09

\begin{abstract}
This study represents the improvement of stability of solar cell characteristics above room temperature. We have analyzed theoretically the temperature dependence of three major characteristics of solar cell using $\mathrm{Ge}$ and $\mathrm{InN}$ based quantum dot in the active layer of the device structure. Among the major characteristics of solar cell we have investigated the rate of change of open circuit voltage, short circuit current and the output power of solar cell with respect to temperature. Numerical results obtained are compared. The comparison results reveal that the rate of change of open circuit voltage, short circuit current and output power have been reduced significantly using InN based quantum dot in the active layer of the solar cell. Hence the improvement in stability of these characteristics above room temperature has been achieved by using InN based quantum dot in the active layer of the solar cell.
\end{abstract}

Keywords: Quantum Dot, Solar Cell, Open Circuit Voltage, Short Circuit Current, Output Power

\section{INTRODUCTION}

Power crisis has become a severe problem all over the world. Different sources of energy pollute our environment in different ways and in different degrees (Mahrane et al., 2010). Therefore researchers are looking for more environment friendly sources of energy. In earlier studies, (Al-Badi, 2013; Jwo et al., 2013) reported that solar energy is the cleanest form of energy. The proper utilization of solar energy is the major challenge to the researchers in the era of modern science and technology particularly to protect global warming and fossil fuel depletion (Chiaro et al., 2008; Jangra et al., 2012).

The solar cell is used to convert the most environmental friendly energy ever discovered i.e. solar energy into the electrical energy (Hepbasli and Alsuhaibani, 2011). It has been reported that the active layer of the earlier solar cells was mainly fabricated with semiconductor elements like $\mathrm{Si}$ and $\mathrm{Ge}$ (Fan et al., 2010). The active layer of the advanced solar cells is composed of binary semiconductor compounds like GaAs, InAs, GaSb and so on (Andreev et al., 2009; Huang et al., 2011) Recently researchers have found that InN offer substantial potential in developing high efficient devices, both because of measurements indicating that the band gap on $\mathrm{InN}$ is lower than other group-III nitrides materials and also due to other unique material properties, such as the strong polarization and affiliation piezoelectric effects (Hwang et al., 2012; Humayun et al., 2012a). Additionally in the last few years, self-organized Quantum Dots (QDs) have been used in Photovoltaic (PV) devices to increase the sub-band-gap photon absorption and the energy conversion efficiency (Guimard et al., 2009). InN based quantum dot is considered as the best alternative active layer material for the enhancement of the stability of the device characteristics.

Corresponding Author: Mohd Abdur Rashid, School of Electrical Systems Engineering, University Malaysia Perlis, Perlis, Malaysia 


\section{MATERIALS AND METHODS}

The temperature plays an important role on the open circuit voltage, short circuit current and the power output of the solar cell. The rate of change of these characteristics has been analyzed theoretically in this present research work.

Rosli et al. (2013) reported that the open circuit voltage of solar cell is related to the bandgap energy of the active layer semiconductor material of the solar cell by the following equation:

$$
V_{o c}(T)=\frac{E_{g}(T)}{q}-V_{\text {ocdeficit }}
$$

where, $E_{g}(T)$ is the bandgap energy of the active layer semiconductor material of the solar cell at any temperature $\mathrm{T}, \mathrm{q}$ is the charge of electron and $\mathrm{V}_{\text {ocdeficit }}$ is the open circuit voltage deficit.

Again the effect of temperature on the bandgap energy of semiconductor is described by Varshni's equation (Humayun et al., 2012b), which is written as:

$E_{g}(T)=E_{g}(0)-\frac{\gamma T^{2}}{T+\beta}$

where, $\mathrm{E}_{\mathrm{g}}(0)$ is the energy band gap at $\mathrm{T}=0 \mathrm{~K}$. In this present research work we have used $\mathrm{InN}$ and Ge based quantum dot in the active layer of the solar cell structure. The band gap and other parameters of InN and those of Ge are given in Table 1 and 2 (Zeghbroeck, 2007; Humayun et al., 2012a).

To investigate the effect of temperature on the fluctuation of open circuit voltage we used Equation (1) and (2). We have put the value of $E_{g}(T)$ from Equation (2) into Equation (1) then taking the first derivative on the both side of the obtained Equation with respect to temperature we get:

$$
\frac{d V_{o c}(T)}{d T}=-\frac{\gamma}{q} \frac{T(T+2 \beta)}{(T+\beta)^{2}}
$$

Here the (-ve) sign indicates that the open circuit voltage of the solar cell decreases with the increase in temperature or vice versa. Now considering only the magnitude of the rate of change of band gap energy with respect to temperature we have:

$$
\left|\frac{\mathrm{dV}_{\mathrm{oc}}(\mathrm{T})}{\mathrm{dT}}\right|=\frac{\gamma}{\mathrm{q}} \frac{\mathrm{T}(\mathrm{T}+2 \beta)}{(\mathrm{T}+\beta)^{2}}
$$

Table 1. Parameters used for Ge and InN

\begin{tabular}{lcr}
\hline Material & Ge & \multicolumn{1}{c}{ InN } \\
\hline $\mathrm{Eg}(0)(\mathrm{eV})$ & 0.7437 & 0.700 \\
$\gamma(\mathrm{meV} / \mathrm{K})$ & 0.477 & 0.414 \\
$\beta(\mathrm{K})$ & 235.000 & 545.000 \\
\hline
\end{tabular}

Table 2. Values of parameters used in this research work

\begin{tabular}{lll}
\hline Symbol s & Parameter s & Value \\
\hline $\mathrm{q}$ & Charge of electron & $1.6 \times 10^{-19} \mathrm{C}$ \\
$\mathrm{K}$ & Boltzmann's Constant & $1.38 \times 10^{-23} \mathrm{~J} / \mathrm{K}$ \\
\hline
\end{tabular}

The short circuit current of solar cell is given by the following Equation (Zeghbroeck, 2007):

$I_{S C}=I_{S} e^{\left(\frac{\mathrm{qV}_{\mathrm{OC}}}{\mathrm{KT}}-1\right)}$

In order to investigate the rate of change of short circuit current with respect to temperature we need to differentiate on the both side of Equation (5) with respect to temperature. By taking first derivative on the both side of the Equation 5 we get:

$\frac{d I_{S C}(T)}{d T}=-\frac{q}{K T^{2}} \frac{d V_{O C}(T)}{d T} I_{S} e^{\left(\frac{v_{O C} q}{K T}-1\right)}$

Then putting the value of $\frac{\mathrm{dV}_{\mathrm{oc}}(\mathrm{T})}{\mathrm{dT}}$ from Equation (3) we get:

$\frac{\mathrm{dI}_{\mathrm{SC}}(\mathrm{T})}{\mathrm{dT}}=\frac{\gamma}{\mathrm{KT}} \frac{(\mathrm{T}+2 \beta)}{(\mathrm{T}+\beta)^{2}} \mathrm{I}_{\mathrm{S}} \mathrm{e}^{\left(\frac{\mathrm{qV}_{\mathrm{OC}} \mathrm{q}}{\mathrm{KT}}-1\right)}$

The output power of solar cell is given by the following equation:

$\mathrm{P}_{\text {out }}=\mathrm{V}_{\mathrm{oc}} \mathrm{I}_{\mathrm{SC}}$

Now to investigate the rate of change of output power of the solar cell with respect to temperature we need to differentiate on the both side of Equation (8) we obtain:

$\frac{\mathrm{dP}_{\text {out }}(\mathrm{T})}{\mathrm{dT}}=\mathrm{V}_{\text {oc }}(\mathrm{T}) \frac{\mathrm{dI}_{\mathrm{SC}}(\mathrm{T})}{\mathrm{dT}}+\mathrm{I}_{\mathrm{SC}}(\mathrm{T}) \frac{\mathrm{dV}_{\mathrm{OC}}(\mathrm{T})}{\mathrm{dT}}$

Now using Equation 1-6 and putting the values in Equation (9) we get Equation 10: 


$$
\begin{aligned}
& \frac{\mathrm{dP}_{\text {OUT }}(\mathrm{T})}{\mathrm{dT}}=\frac{\gamma}{\mathrm{KT}} \frac{(\mathrm{T}+2 \beta)}{(\mathrm{T}+\beta)^{2}} \mathrm{I}_{\mathrm{S}}\left(\frac{\mathrm{E}_{\mathrm{g}}}{\mathrm{e}}-\mathrm{V}_{\text {OCdeficit }}\right) \mathrm{e}^{\left(\frac{\mathrm{v}_{\mathrm{OC}} \mathrm{KT}}{\mathrm{KT}}-1\right)} \\
& +\mathrm{I}_{\mathrm{S}} \frac{\gamma}{\mathrm{q}} \frac{\mathrm{T}(\mathrm{T}+2 \beta)}{(\mathrm{T}+\beta)^{2}} \mathrm{e}^{\left(\frac{\mathrm{v}_{\mathrm{OC}} \mathrm{q}}{\mathrm{KT}}-1\right)}
\end{aligned}
$$

\section{RESULTS}

This section presents the comparative analysis of the effect of temperature on the rate of change of the major characteristics of solar cell using $\mathrm{Ge}$ and $\mathrm{InN}$ based quantum dot in the active layer of the solar cell. The fluctuation of open circuit voltage of solar cell with respect to temperature has been analyzed by using Equation (4). This characteristic has been presented in Fig. 1. Then we have analyzed the variation of short circuit current and output power using Equation (6) and (10). These characteristics are shown in Fig. 2 and 3, respectively. Different parameters used in the numerical calculation is given in Table $\mathbf{1}$ and 2.

Figure 1 presents the fluctuation of the open circuit voltage of solar cell with respect to temperature. The solid line and the dashed line represents the rate of change of open circuit voltage of solar cell using $\mathrm{InN}$ and Ge based quantum dot in the active layer of the solar cell respectively. The rate of change of open circuit voltage of solar cell increases with the increase of temperature both for using $\mathrm{Ge}$ and $\mathrm{InN}$ based quantum dot in the active layer of the solar cell. However, from the numerical result it is ascertained that the rate of change of open circuit voltage of solar cell has been reduced significantly by using InN based quantum dot in the active layer of the solar cell.

Figure 2 is plotted using Equation (1), (2) and (7). It shows the variation of the short circuit current of solar cell with respect to temperature. The solid line and the dashed line represents the rate of change of short circuit current of solar cell using $\mathrm{InN}$ and $\mathrm{Ge}$ based quantum dot in the active layer of the solar cell respectively. The rate of change of short circuit current of solar cell decreases exponetially with the increase of temperature both for applying $\mathrm{Ge}$ and $\mathrm{InN}$ based quantum dot as the active layer material of the solar cell as shown in figure.

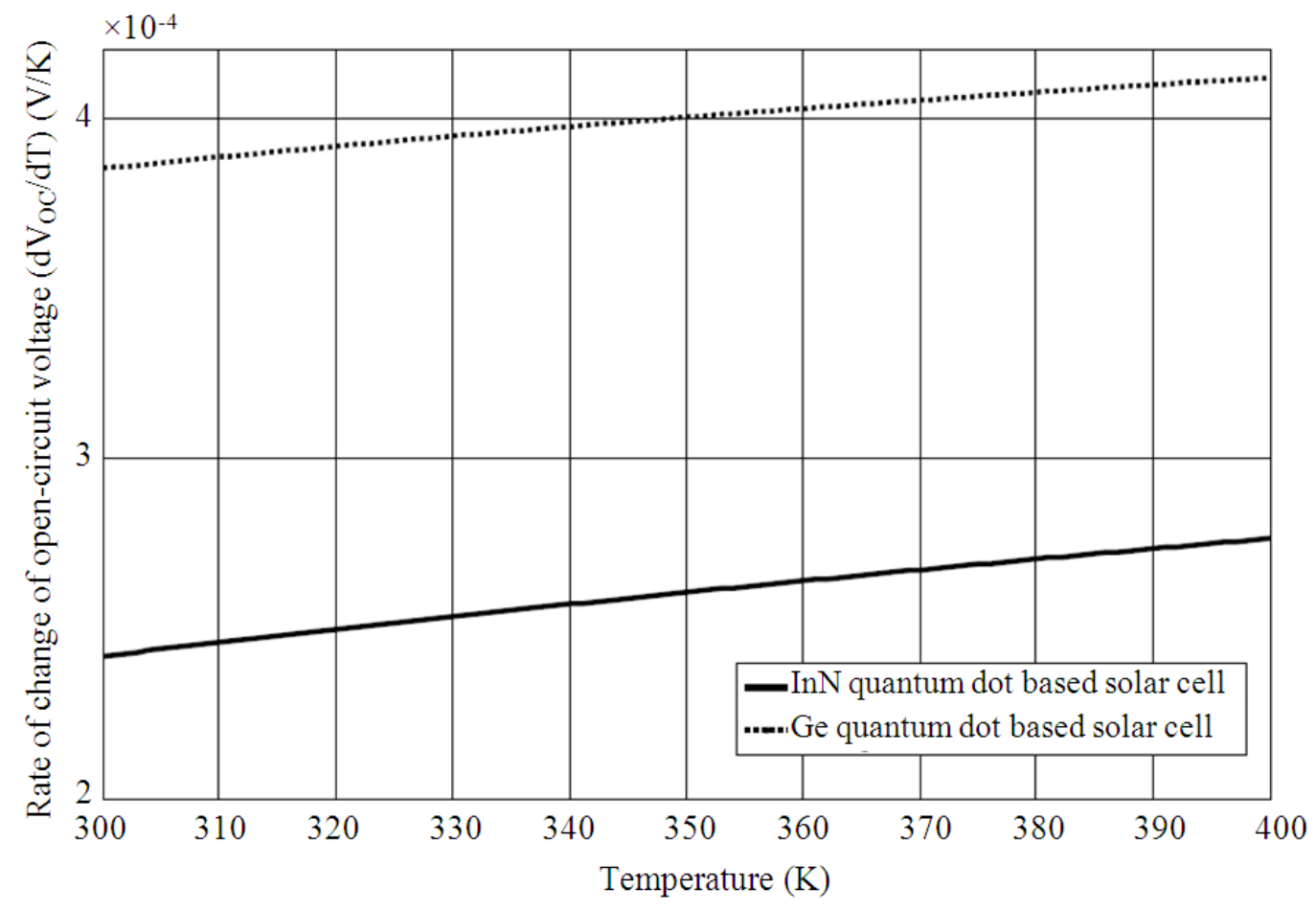

Fig. 1. Fluctuation of open circuit voltage of solar cell with respect to temperature. The solid line and the dashed line represents the open circuit voltage fluctuation using $\mathrm{InN}$ and Ge based quantum dot in the active layer of the solar cell structure respectively 


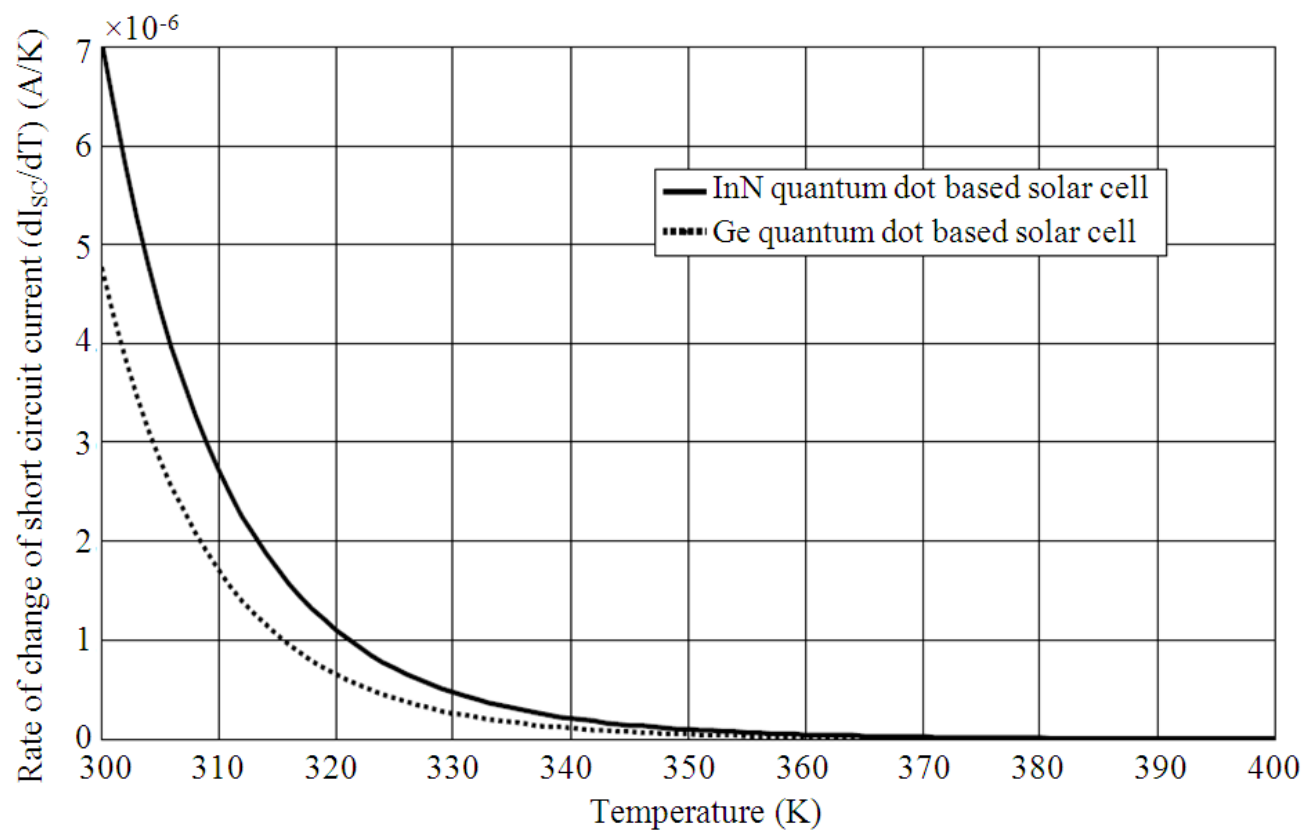

Fig. 2. Variation of short circuit current of solar cell with respect to temperature. The solid line and the dashed line represents the short circuit current variation using InN and Ge based quantum dot in the active layer of the solar cell respectively

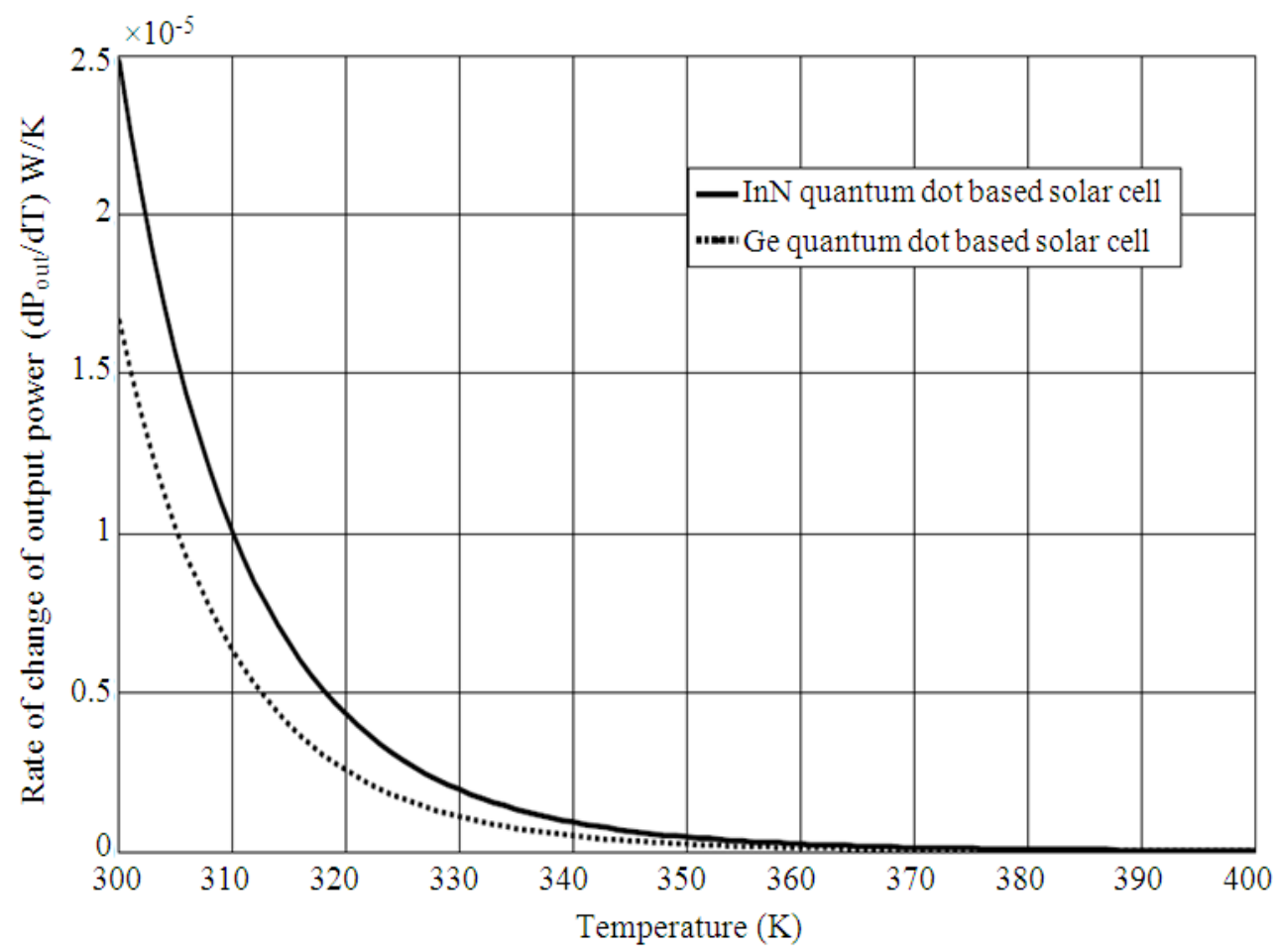

Fig. 3. Rate of change of output power of solar cell with respect to temperature. The solid line and the dashed line represents the output power fluctuation using $\mathrm{InN}$ and Ge based quantum dot in the active layer of the solar cell respectively 
However graph presented in Figure 2 clearly shows that the rate of change of short circuit current using InN based quantum dot is less than that obtained using Ge based quantum dot in the active layer of the solar cell structure at high temperature.

Figure 3 shows the rate of change of the output power of solar cell with respect to temperature. The solid line and the dashed line represents the rate of change of output power of solar cell using $\mathrm{InN}$ and $\mathrm{Ge}$ based quantum dot in the active layer of the solar cell respectively. The rate of change of output power of solar cell decreases nonlinearly with the increase of temperature both for $\mathrm{Ge}$ and $\mathrm{InN}$ based quantum dot based solar cell as shown in figure. However from the comparative result shown in Fig. 3 it is revealed that the rate of change of output power has been reduced notably using InN based quantum dot in the active layer of the solar cell structure high temperature.

Finally from the above discussion it is ascertained that InN based quantum dot provides the higher stability of the solar cell characteristics at high temperature.

\section{DUSCUSSION}

Previous stuides show that the performance improvement of optoelectronic devices can be achieved by using quantum dot as the active layer material (Humayun et al., 2013). The authors were motivated to invetigate the performance improvement of solar cell characteristics applying quantum dot. In this work, we have analyzed the rate of change of open circuit voltage, short circuit current and power output of solar cell with respect to temperature using Ge and InN based quantum dot in the active layer of the solar cell. It has been proved theoritically that InN based quantum dot improves the stability of the major characteristics of solar cell. The theoritical findings of this research work can be a doorway for the researchers to facilate the InN quantum dot based solar cell in real life after the experimental validation.

\section{CONCLUSION}

This study highlights the improvement of the stability of the major three characteristics of quantum dot based solar cell above room temperature. We have studied extensively the rate of change of all these characteristics of solar cell with respect to temperature using Ge and InN based quantum dot in the active layer of the solar cell structure. The comparison of the numerical results ascertain that the rate of change of open circuit voltage, short circuit current and the output power have been reduced appreciably above room temperature by using $\mathrm{InN}$ based quantum dot in the active layer of the solar cell structure. Therefore it is ascertained that InN based quantum dot will be a suitable material for the improvement of solar cell characteristics above room temperature.

\section{REFERENCES}

Al-Badi, A.H., 2013. Pre-feasibility study of stand-alone hybrid energy systems for applications in ecohouses. Int. J. Sustain. Eng., 6: 48-54. DOI: 10.1080/19397038.2012.677491

Andreev, V., S. Sorokina, N. Timoshina, V. Khvostikov and M. Shvarts, 2009. Solar cells based on gallium antimonide. Semiconductors, 43: 668-671. DOI: 10.1134/S1063782609050236

Chiaro, B.D., S. Payne and T. Dutzik, 2008. On the Rise: Solar Thermal Power and the Fight Against Global Warming. 1st Edn., Environment America Research and Policy Center, Washington, pp: 37.

Fan, Q.H., C. Chen, X. Liao, X. Xiang and S. Zhang et al., 2010. High efficiency silicon-germanium thin film solar cells using graded absorber layer. Solar Energy Mater. Solar Cells, 94: 1300-1302. DOI: 10.1016/j.solmat.2010.03.006

Guimard, D., D. Bordel, R. Morihara, Y. Wakayama, K. Tanabe and M. Nishioka et al., 2009. InAs/Sb:GaAs quantum dot solar cells grown by metal organic chemical vapor deposition. Proceedings of the 34th IEEE Photovoltaic Specialists Conference, Jun. 712, IEEE Xplore Press, Philadelphia, PA., pp: 17801784. DOI: 10.1109/PVSC.2009.5411475

Hepbasli, A. and Z. Alsuhaibani, 2011. A key review on present status and future directions of solar energy studies and applications in Saudi Arabia. Renew. Sustain. Energy Rev., 15: 5021-5050. DOI: 10.1016/j.rser.2011.07.052

Huang, S., A.V. Semichaevsky, L. Webster, H.T. Johnson and R.S. Goldman, 2011. Influence of wetting layers and quantum dot size distribution on intermediate band formation in InAs/GaAs superlattices. J. Applied Phys., 110: 073105-073105. DOI: $10.1063 / 1.3631785$

Humayun, M.A., M.A. Rashid, F.A. Malek and A.N. Hussain, 2012a. Effect of lattice constant on band gap energy optimization and stabilization of high temperature inxga1-xn quantum dot lasers. J. Russian Laser Res., 33: 387-394. DOI: 10.1007/s10946-012-9294-7 
Humayun, M.A., M.A. Rashid, F.A. Malek, A.N. Hussain and I. Daut, 2012b. Design of quantum dot based laser with ultra-low threshold current density. Applied Mech. Mater., 229-23: 1639-1642. DOI: 10.4028/www.scientific.net/AMM.229-231.1639

Humayun, M.A., M.A. Rashid, F. Malek, A. Yusof, F. S. Abdullah, N.B., Ahamad, 2013. A comparative study of confined carrier concentration of laser using quantum well and quantum dot in active layer. Adv. Mater. Res., 701: 188-191.

Hwang, J., A.J. Martin, J.M. Millunchick and J.D. Phillips, 2012. Thermal emission in type-II GaSb/GaAs quantum dots and prospects for intermediate band solar energy conversion. J. Applied Phys., 111: 074514074514. DOI: $10.1063 / 1.3703467$

Jangra, M. K., K. P. S. Parmar and N. K. Yadav, 2012. Reduction of global warming by using renewable energy resources: A mathematic approach. Int. J. Comput. Sci. Telecommun., 3: 37-41.
Jwo, C., S. Chen, H. Chang, Y. Su and J. Chen, 2013. Solar energy and clean energy: Trends and developments. Int. J. Photoen., 2013: 2-2. DOI: 10.1155/2013/749167

Mahrane, A., M. Chikh and A. Chikouche, 2010. Energy management for standalone PV system. Jordan J. Mech. Indus. Eng., 4: 117-120.

Rosli, F. A., M.A. Rashid, F. Malek, M. Othman and A.A. Zaidi et al., 2013. Minimization of open circuit voltage fluctuation of quantum dot based solar cell using InN. Applied Mech. Mater., 372: 586-589.

Zeghbroeck, B.V., 2007. Principles of Semiconductor Devices and Heterojunctions. 1st Edn., Prentice Hall PTR, Upper Saddle River, ISBN-10: 0130409049, pp: 450. 